\title{
The Socratic Fallacy and the Epistemological Priority of Definitional Knowledge
}

\section{David Wolfsdorf}

\section{Geach and the Socratic Fallacy}

In 1966 P.T. Geach published a paper on Euthyphro in which he criticized Plato's Socrates for several logical errors. The most widely discussed has been what Geach called the 'Socratic fallacy'. According to Geach, Plato's Socrates is committed to the following two propositions:

(A) If you know that you are correctly predicating a given term ' $\mathrm{T}$ ', you must know what it is to be $T$, in the sense of being able to give a general criterion for a thing's being $\mathrm{T}$.

(B) It is no use to try to arrive at the meaning of ' $\mathrm{T}$ ' by giving examples of things that are $\mathrm{T}^{2}$

This is why Geach thinks commitment to (A) and (B) is fallacious:

We know heaps of things without being able to define the terms in which we express our knowledge. Formal definitions are only one way of elucidating terms; a set of examples may in a given case be more

1 This paper is dedicated to the Philosophy Department at Boston University, especially Charles Griswold and David Roochnik, in gratitude for welcoming me under their aegis over the past two years.

2 P.T. Geach, 'Plato's Euthyphro: An Analysis and Commentary', Monist 50 (1966) 369-82, at 371 
useful than a formal definition ... If the parties to a discussion are agreed, broadly speaking, about the application of a term, then they can set out to find a criterion for applying it that shall yield the agreed application. On the other hand, if they are agreed on the criterion for applying the term, then they can see whether this criterion justifies predicating " $T$ " of a given example. But if there is no initial agreement either on examples of things that certainly are $T$ or on criteria for predicating " $T$ ", then the discussion is bound to be abortive; the parties to it cannot know what they are about - they do not even know whether each of them means the same by saying " $T$ ". Any profit they gain from the discussion will be per accidens; per se the discussion is futile. $^{3}$

In considering Geach's accusation, I begin with two qualifications. First, (A) and (B) are expressed as general semantico-epistemological principles. The symbol ' $\mathrm{T}$ ' implicitly ranges over all predicates. It is at least questionable whether Socrates is committed to principles of such generality. He is mainly interested in human virtue and its putative components. So it will be prudent, at least initially, to restrict consideration to this domain. Second, it is appropriate to alter (A) and (B) from the meta-linguistic terms in which Geach formulated them to object-language terms more fitting Socrates' mode of conceptualization. Socrates is not interested in the meanings of words, but in the identity of human virtue and its components. Thus, (A) and (B) misrepresent Socrates. A better formulation of $(A)$ is:

(A') If one does not know what $F$ is, one cannot know for any $x$ whether $x$ is an instance of $F$ (where the symbol ' $F$ ' ranges over the domain of human virtue and its components).

$\left(\mathrm{A}^{\prime}\right)$ states that definitional knowledge of $F$ is epistemologically prior to knowledge of instances of $F$. Accordingly, (B) should be reformulated as:

(B') One cannot achieve definitional knowledge of $F$ through the use of instances of $F$. 
Thus, Geach's charge amounts to the following. If one knows that the members of a set exemplify $F$, then one can use those members to determine what $F$ is. Alternatively, if one knows what $F$ is, one can use that knowledge to determine whether a given entity is an instance of $F$. But if one neither knows what $F$ is nor which instances are of $F$, then pursuit of knowledge of $F$ or of knowledge of instances of $F$ is futile. Furthermore, Geach believes that $\left(A^{\prime}\right)$ is simply wrong because in many cases we know instances of $F$ without being able to give a definition of $F$.

A common response to Geach is that Socrates in fact uses examples of $F$ in the pursuit of definitional knowledge of $F$. Therefore, Socrates cannot be committed to ( $\left.A^{\prime}\right)$. For example, in Laches Socrates grants that agents who perform paradigmatic hoplite deeds (remain in rank, defend against the enemy, and do not flee) exemplify courage, but he suggests that agents who perform a number of other act-types also exemplify courage. Thus, he encourages Laches to consider what all such agents have in common: 'So try again and first tell me this: What is that thing that is the same in all cases?'4

Accordingly, it has been argued that Socrates is not committed to the view that definitional knowledge of $F$ is epistemologically prior to knowledge of all instances of $F$. Rather, definitional knowledge of $F$ is necessary for borderline or controversial cases, for example, whether Euthyphro's father's peculiar homicide is unholy. More broadly, then, definitional knowledge of $F$ is necessary for ethical expertise, yet one may know a number of common instances of $F$ without being an expert.

Such a position requires that claims Socrates makes resembling ( $A^{\prime}$ ) actually reflect a weaker principle. Yet, I contend, evidence from a number of early dialogues, in particular from the standardly accepted early definitional dialogues indicates that Plato actually intended to advance Socrates' commitment to a set of principles that are collectively even stronger than $\left(A^{\prime}\right)$. $\left(A^{\prime}\right)$ is currently labeled ' $(P)$ ', a practice with which I will hereafter conform; hence:

(P) If one does not know what $F$ is, one cannot know for any $x$ whether $x$ is an instance of $F$.

The evidence indicates that in addition to $(\mathrm{P})$ Socrates is committed to:

4 La 191e10-11. Below we will see that in fact Socrates rarely uses examples in the way that Geach suggests one might or should. 
(D) If one does not know what $F$ is, then one cannot know whether $F$ has a property $P$ (where the attribution of $P$ to $F$ is ethically substantive).

The reason for the parenthetical qualification in (D) is that, otherwise, in a discussion of, say, justice, Socrates could not claim to know that his interlocutor and he were speaking of justice or whether the name of justice was 'justice'. The fact is that Socrates simply does not entertain such matters. Presumably, he would find them trivial. ${ }^{5}$

The conjunction of $(P)$ and $(D)$ yield:

(PD) If one does not know what $F$ is, then one cannot know anything of ethical substance about $F$.

Let us look at the relevant passages and the work of those who have argued that Socrates is not committed to (P), (D), or (PD).

\section{II i Vlastos' Denial of the Socratic Fallacy}

Vlastos' (as well as Beversluis') position depends upon the segregation of two sets of early dialogues, the so-called elenctic and transitional dialogues. The transitional dialogues whose content presently matters include Hippias Major and Meno. ${ }^{6}$ Crucial to Vlastos' distinction between elenctic and transitional dialogues is the view that in the elenctic dialogues Socrates' investigative method is adversarial insofar as 'Socrates'

5 I am grateful to an anonymous referee for pointing out this difficulty.

6 John Beversluis ('Does Socrates Commit the Socratic Fallacy?', American Philosophical Quarterly 24 [1987] 211-23), who closely follows Gregory Vlastos ('Socrates' Disavowal of Knowledge', Philosophical Quarterly 35 [1985] 1-31) writes: '[in the transitional dialogues Socrates is] a thinker whose views are often radically at odds with those of his counterpart in the early [i.e., elenctic] dialogues.' (221, $n 4$, cited from Hugh H. Benson, 'The Priority of Definition and the Socratic Elenchus', Oxford Studies in Ancient Philosophy, 8 [1990] 19-65, at 24.) One explanation for this transition is that Plato became increasingly interested in mathematics and the axiomatic deductive method, where 'the priority of definition in the artificial languages of axiomatic method is a commonplace.' (Note that this is Benson's description [1990, $24-5, n$ 11] of Vlastos' account in an unpublished manuscript of Vlastos', on which cf. Vlastos, 'Elenchus and Mathematics: A Tuming Point in Plato's Philosophical Development, American Joumal of Philology 109 [1988] 362-96.) 
formal role is never to defend a thesis of his own, but only to examine the thesis of his interlocutor." In contrast, Vlastos believes that in the so-called transitional dialogues Socrates abandons the adversarial method. This is false. As Benson notes, Socrates' conversations with Hippocrates in Protagoras, with Melesias in Laches, and with Crito in Crito are not adversarial. Furthermore, in the investigations in Meno and Hippias Major, Meno and Hippias respectively propose the first three definitions. Moreover, in Laches Nicias' definition crucially depends upon Socrates' view that a man is good only insofar as he is knowledgeable; and in Euthyphro, the fourth definition crucially depends upon Socrates' suggestion that the holy is a part of the just. ${ }^{8}$

More generally, as I have recently argued, there is no 'demise of the elenchus' in the so-called transitional dialogues. Throughout the early definitional dialogues Socrates pursues definitional knowledge of $F$ in a consistent manner. Specifically, he pursues true definitions of $F$ by evaluating proposals (made by himself or his interlocutors) through consideration of their consistency with conditions of the identity of $F$ (so-called $F$-conditions) that he introduces and to which he is committed. Furthermore, this manner of pursuing definitions is not elenctic in the idiosyncratically Vlastosian sense, for Socrates does not try to refute definitions proposed by his interlocutors. Rather, he conceives of himself as learning from his interlocutors (for example, Hippias, Thrasymachus, or Euthyphro) or as engaged in a joint investigation with them (Critias, Laches and Nicias, or Polemarchus), where his own contributions are intended to be cooperative and supportive - although unwaveringly directed toward the discovery of truth. ${ }^{10}$ Consequently, the evidence from Hippias Major and Meno for Socrates' commitment to (PD) cannot be segregated by appeal to a shift in Socrates' method. And since Vlastos and Beversluis concede that the evidence from these texts commits Socrates to (PD), their argument collapses.

7 Vlastos (1988) 5, cited from Benson (1990) 25

8 Cf. Benson (1990) 25-6.

9 The phrase is taken from the title of Vlastos' appendix, 'The Demise of the Elenchus in the Euthydemus, Lysis, and Hippias Major' in Socratic Studies (New York: Cambridge University Press 1994), 29-33.

10 Cf. David Wolfsdorf, 'Socrates' Pursuit of Definitions', Phronesis 48 (2003b) 271-312. 
The pertinent passages are:

(1) [Hippias Major] How do you know (oio $\alpha \alpha$ ) what sort of things are beautiful and ugly? Come now, can you say what the beautiful is?"

(2) [Hippias Major] He asks me if I am not ashamed to talk about beautiful practices, when I have clearly been refuted concerning the beautiful, to the effect that I don't know (oi $\delta \alpha$ ) what the thing itself is. "And yet," he will say, "how will you know (हiorı) whether or not someone has spoken beautifully, or done any other thing whatsoever, when you do not know ( $\dot{\alpha} \gamma v 0 \hat{v}$ ) the beautiful?"12

(3) [Meno] I am so far from knowing (Eidéval) whether or not virtue is

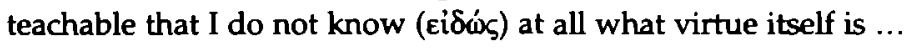
Not knowing (Eibiog) at all what a thing is, how would I know (eideinv) what sort of thing it is? Or do you think that it is possible for someone who is completely unacquainted with (rrvóroki)

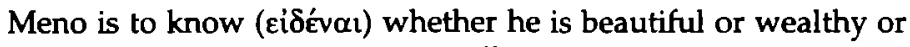
well born or the opposite of these? ${ }^{13}$

(4) [Meno] We shall know (eioó $\mu \varepsilon \theta \alpha$ ) the certainty of this [namely that virtue comes to us by divine inspiration] when, before we attempt to seek how virtue comes about in men, we attempt to seek what virtue itself is by itself. ${ }^{14}$

\section{II ii Brickhouse and Smith's and Lesher's Denials of (P) and (D)}

In contrast to Vlastos and Beversluis, Lesher and Brickhouse and Smith deny that the evidence of the so-called transitional dialogues must be segregated. Still, they argue that this evidence does not commit Socrates to (PD). Lesher does not discuss (1) or (4). However, since the respective passages come from the same dialogues, it is reasonable to assume that his interpretation of (1) would be consonant with his interpretation of

11 Hp Ma 286c8-d2

12 Нp Ma 304d5-e2

13 Meno 71a5-b7

14 Meno 100b4-6 
(2), which he does discuss, and that his interpretation of (4) would be consonant with his interpretation of (3), which he does discuss. Lesher claims that Socrates is committed to (D), but not (P) ${ }^{15} \mathrm{He}$ admits (3) and, I am assuming, (4) as evidence that Socrates is committed to (D). But he does not admit (2) as evidence of (P). Instead, he interprets (2) as committing Socrates to the sufficiency of knowledge of $F$ for knowledge of examples of $F .^{16}$ In other words, knowledge of $F$ would explain knowledge of examples of $F$; however, there are other means of acquiring knowledge of examples of $F$. This, Lesher believes, is precisely what the question in (2) is asking. How, that is, by what means, since not by knowledge of $F$, do you know examples of $F$ ?

15 'In the Laches, ignorance of the essence of virtue is said to prevent us from knowing how best to attain virtue (185e5-190b1), and this is only one instance of the more general problem (mentioned at Charmides 176a6-8, Meno 71 and elsewhere) that ignorance of a thing's essential nature prevents us from knowing what other attributes it may possess or lack. None of these texts however amounts to the essentialist thesis at hand: that not knowing the essence of $F$, neither can one know whether a particular thing is F or not' O.H. Lesher, 'Socrates' Disavowal of Knowledge', Journal of the History of Philosophy 25 [1987] 284-5).

16 If $I$ ask someone "how do you know $X$ when you don't know $Y$ ?" I might be attempting to discredit his claim to know $X$, but I needn't be. Alternatively, leaving undecided the question of whether he knows $X$ or not, I might ask him how he knows $X$ when one way sufficient for knowing $X$ (i.e., knowing $Y$ ) is unavailable to him. In these cases, lacking knowledge of the essence of beauty and friendship, Socrates cannot explain how he knows by appealing to the knowledge of their essence (though that would indeed explain it), but his inability to provide this explanation does not imply that he cannot have knowledge, or that he could have no other basis on which to support his claim to know. An inability to explain how one knows subjects one to ridicule and contempt, but it does not exclude the possibility that one knows after all. The essentialist epistemic thesis is therefore stronger than any Platonic text can justify; nothing so far said prevents Socrates from knowing that $a$ is $F$ even when he does not know what the $F$ is, and he seems not to have been bothered by any such restriction' (ibid., 285). Lesher also cites Vlastos here: 'As Vlastos noted, "in the Crito Socrates has no trouble ascertaining that escape would be unjust without invoking any general definition of 'justice' or 'injustice'."' $(285, \mathrm{n} 13$; the citation is from Vlastos, 1985, 23.) Vlastos' point is irrelevant, though, since Socrates does not claim to know that escaping would be unjust. Rather, he strongly believes it. The situation is similar to that in Gorgias where Socrates strongly affirms that it is better to suffer ham than to do it, but he disclaims knowledge of this. The question, then, is why in Crito Socrates does not explicitly indicate that although he believes escape would be unjust, he does not know this. 
Consideration of the broader context in which (2) is embedded exposes the problem of this interpretation:

So whenever I go home to my own house and he hears me saying these things, he asks me if I am not ashamed that I have the face to talk about beautiful practices, when it is so plainly shown, to my confusion, that I do not even know what the beautiful itself is. "And how are you to know," he will say, "either who produced a discourse or anything else whatsoever, beautifully, or not, when you are ignorant of the beautiful? And when you are in such a condition, do you think it is better for you to be alive than dead?"

Clearly Socrates' alleged friend is not wondering, as an epistemological point of concern, by what means other than knowledge of $F$ Socrates can know examples of $F$. Nor is he stressing the strangeness of the fact that Socrates knows examples of $F$ in the absence of knowledge of $F$ itself. Rather, he is abusing Socrates for daring to consider certain entities as instances of $F$ without knowing what $F$ is. The implication is that one cannot know whether certain entities are instances of $F$ if one does not know what $F$ is. $^{18}$

Like Lesher, Brickhouse and Smith do not segregate the so-called elenctic and transitional dialogues. Even so, they argue that Socrates is not committed to (P) or (D). They discuss eight passages that have been thought to provide evidence for Socrates' commitment to (P) and (D), and they explain these passages on the basis of an alternative conception of Socrates' commitment to the epistemological priority of definitional knowledge. ${ }^{19}$ According to Brickhouse and Smith, Socrates is committed to the view that:

17 Hp Ma 304d4-e3

18 It should be added that for comic effect the alleged friend is of course speaking hyperbolically, as elsewhere in Hippias Major. Lacking knowledge of $F$ should not be grounds for suicide. Moreover, in many early dialogues Socrates discusses examples of $F$ without knowing $F$. But $I$ take his severity here to mean that one should not be ignorant of the fact that without knowledge of $F$ one cannot know examples of $F$. Thus, if one speaks of examples of $F$, one should do so tentatively.

19 The eight passages are: Hp Ma 304d5-e3; Euthphr 4e1-5d1, 6e3-6; La 189e3-190b1; Meno 71a5-b7; Prot 312c1-4; and R I, 354c1-3. 
(BSP) One must know the definition of $F$ before one can be in a position to judge in general which things are and which things are not' instances of $F^{20}$

Although akin to $(\mathrm{P}),\left(\mathrm{BS}_{\mathrm{P}}\right)$ differs insofar as it permits that one who lacks definitional knowledge of $F$ may still know certain instances of $F$. In contrast, the person who has definitional knowledge of $F$ will be an expert in matters of virtue, that is 'be in a position to judge in general' instances of $F$. In support of their position, then, Brickhouse and Smith must show that the passages that seem to support Socrates' commitment to (P) and (D) are best interpreted as concerning the role of definitional knowledge in expertise or authoritative judgment. Furthermore, they must show that Socrates believes that it is possible to know certain instances of $F$ without definitional knowledge.

In this section I will discuss Brickhouse and Smith's treatment of (1) and (2). I will postpone for a later section their treatment of certain passages in Euthyphro pertinent to (P). With respect to (2), Brickhouse and Smith claim that:

The sense of challenge is that Socrates is in no position to play the part of a judge, to lay claim to being able to tell what is and what is not beautiful. But the question "Who are you to judge?" does not challenge one's claim to judge any case at all; it only challenges one's ability to judge in general; so "How will you know?" only challenges Socrates' general access to the pertinent knowledge. ${ }^{21}$

The correct interpretation of (2) depends on the correct interpretation of (1) since (2) simply reiterates (1). The context in which (1) occurs prompts the investigation of the beautiful, and in stating (2) at the end of the failed investigation, Socrates is emphasizing the importance of investigating the definition of the beautiful. Here is the broader context in which (1) occurs:

Recently ... someone threw me into a state of aporia as I was criticizing certain things in speeches as base and praising others as beautiful. With

20 Thomas C. Brickhouse and Nicholas D. Smith, Plato's Socrates (New York: Oxford University Press 1994), 46

21 Ibid., 46-7 
great disdain he questioned me in the following way: "Socrates, how do you know what sorts of things are beautiful and base? Come now, can you tell me what the beautiful is?" But I, useless as I am, was confused and incapable of providing a satisfactory response. I left the company angry and reproaching myself, threatening that at the first opportunity I had to meet one of you wise men, I would listen, learn, and take care so that I could return to the questioner to contest his speech. $^{2}$

Since the text does not state that Socrates was initially attempting to pass value judgments on extraordinary objects or in atypical conditions, we should assume that Socrates' evaluations occurred under normal circumstances. As such, the interrogator was questioning Socrates qua possessor of conventional beliefs. This is, indeed, consistent with Plato's customary portrayal of Socrates as a critic of conventional ethical values. The question 'How do you know what sort of things are beautiful and base? Come now, can you tell me what the beautiful is?' is, then, general. By this, I mean that as interrogator, Socrates is asking himself how he can presume to know that anything is beautiful or base when he lacks knowledge of the identity of the beautiful. Brickhouse and Smith's comment continues:

If one did know what the beautiful is, one could, it seems, act as a judge of beautiful things. But Socrates could well answer his adversary that he is indeed in a position to know in a few cases. ${ }^{23}$

Their comment does not make sense in the context of the Hippias Major passage since Socrates' adversary is Socrates himself. If Socrates believed that he could provide himself with a satisfactory answer - in this case, even though not in general, he knew what was beautiful and base - his question to himself would lack a motivation. In other words, if Socrates believed, in this case, that he knew what was beautiful and base, why would he criticize himself for thinking he knew what, in this case, was beautiful and base? Of course, if could occur to Socrates that although under certain circumstances such as this one he had good reason to believe that he knew what was beautiful. However, he might still be 
prompted by the experience to wonder how he could in general know what was beautiful. But, then, there would be no reason for his frustration and anger with himself.

The force of the question in (1) is that in this case Socrates is operating with assumptions about the soundness of his values, but that these assumptions are dubious and that ethical knowledge requires definitional knowledge. In view of this, consider again (2):

[H] ow will you know whether or not someone has spoken beautifully,

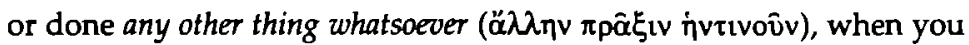
do not know the beautiful?

The idea is that one cannot know that anything whatsoever is beautiful if one lacks knowledge of the beautiful.

Brickhouse and Smith avowedly do not systematically discuss Socrates' commitment to (D) ${ }^{24}$ Still, they do discuss several passages that have been cited as evidence of (D). They claim that (3) involves the principle that one cannot know that a certain type of thing has a certain property unless one knows what that type of thing is. In other words:

(BS $)$ One must know what something is before one can know which predicates to attach to it. ${ }^{25}$

Brickhouse and Smith's treatment of (4), however, indicates that the concept of knowledge in (BS $)$ must be interpreted in a peculiar way. In discussing (4), Brickhouse and Smith draw a distinction between clear knowledge, which they also call 'wisdom', and unclear knowledge. ${ }^{26}$

24 Ibid., 45, n 27

25 Ibid., 52. Brickhouse and Smith consider the following possible exception: 'Now perhaps we could concoct a case in which such a thing were possible: one might have divine authority that something (S) was beautiful without having any idea what $S$ is' (52). In section IV ii, I discuss why Socrates would not consider a person with such information as having knowledge.

26 'Wisdom, we can be sure, brings clear knowledge of the sorts of things Socrates and Meno have been discussing. But what kind of knowledge remains unclear? By now, our answer should be quite predictable: any knowledge which can only assert even entirely confidently - that the fact of the matter is such and such, but which cannot account for why it is so, or how it is that it is so, might very reasonably be identified as unclear knowledge' (ibid., 58). 
They find the concept of clear knowledge expressed in (4): 'we will know tò $\sigma \alpha \varphi \hat{s}$ [clearly, if interpreted adverbially, or the certainty, if interpreted nominally] about this.' And they explain the distinction between clear and unclear knowledge as equivalent to the distinction between knowing that something $p$ is the case and knowing how $p$ is the case. ${ }^{27}$ Accordingly, $\left(\mathrm{BS}_{\mathrm{D}}\right)$ means that one must clearly know what something is before one can clearly know which predicates to attach to it. As such, unclear knowledge of $F^{\prime}$ s properties is possible in the absence of definitional knowledge of $F$.

Brickhouse and Smith's distinction between clear and unclear knowledge or rather knowledge-that and knowledge-how is fundamentally motivated by the fact, first properly emphasized by Vlastos, ${ }^{28}$ that although among the early dialogues Socrates often disavows ethical knowledge, on several occasions he avows some ethical knowledge. In addition to the six examples Vlastos first cited, Kraut, Beversluis, Reeve, Lesher, and Brickhouse and Smith have collected a number of others. Benson has assembled these and added several of his own, bringing the number to thirty-two. ${ }^{29}$

If on thirty-two occasions among the early dialogues Socrates actually avowed some ethical knowledge, it would be startling if he were also committed to (PD). Therefore, any interpreter who argues that Socrates is committed to (PD) must address such avowals. Indeed, an interpreter who examines the topics of the Socratic fallacy and the epistemological priority of definitional knowledge is bound to address this issue.

In a re-examination of Socrates' avowals of knowledge and, more generally, Plato's ethical epistemology in the early dialogues, I have

27 Ibid., 30-45, especially $38 \mathrm{ff}$.

28 Vlastos (1985)

29 Richard Kraut, Socrates and the State (Princeton, NJ: Princeton University Press 1984); Vlastos (1985); Beversluis (1987); Lesher (1987); C.D.C. Reeve, Socrates in the Apology (Indianapolis: Hackett Publishing Company 1989); Brickhouse and Smith (1994); Benson (2000). The thirty-two passages are Grg 486e5-487a3; Prot 357d7-c1; R I 351a5-6; Grg 512b1-2 and 508e6-509b1; and Ap 29a4-b9 (from Vlastos); Ap 18c4-d2, 21a3, 21b4-5, 22c9-d3, 24a4-7, 37b2-8, 37d6-7 (from Lesher); Ap 28a4-8, 30a5, 30c6-8, 31d6-e1, 33b6-8, 41d3-5 (from Reeve); Ion 532d8-e4 and Euthyd 296e3-297a2 (from Brickhouse and Smith); Euthyd 293b7-8, repeated at 293c2 and 295b2-3 (from Kraut); and Grg 521c7-d3; Prot 310b4, 310d2-3, 335a9-b3, 339b4-6, 339c6-7, 356b5-c3, 360e8361a3; Hp Ma 304e6-9; Euthphr 5c4-8, 15d8-e1 (from Benson). 
discussed all thirty-two alleged avowals of knowledge..$^{30}$ The results of that study are consistent with Socrates' commitment to (PD).

The majority of the thirty-two passages cited are not genuine instances of Socrates avowing ethical knowledge. Twenty-seven of these are either not of ethical content or not knowledge claims (but, for example, belief reports). Granted this, still, on five occasions Socrates genuinely avows some non-definitional ethical knowledge, and these are inconsistent with Socrates' commitment to (PD) ${ }^{31}$ Notably, Socrates' five avowals of non-definitional ethical knowledge do not occur in the definitional dialogues where Socrates is portrayed as committed to (PD). Consequently, the inconsistencies are inter-textual, not intra-textual.

The question, then, is why, if Plato portrays Socrates in certain dialogues as committed to (PD), in some other dialogues he portrays Socrates avowing some non-definitional ethical knowledge? The basic answer is that Plato did not compose all of Socrates' utterances to have the same hermeneutic status. Precisely, not all of Socrates' utterances function as propositions that are to be assembled into a consistent set from which the interpreter is then to derive general principles that constitute Plato's philosophical beliefs during the period in which he composed the early dialogues. Some of Socrates' sincere utterances, including Socrates' five sincere avowals of non-definitional ethical knowledge, serve other dramaturgical interests. I discuss these other dramaturgical interests in the paper in question as well as elsewhere. ${ }^{32}$ In short, Socrates' five avowals of non-definitional ethical knowledge among the early non-definitional dialogues are hermeneutically irrelevant to Socrates' commitment to (PD) in the early definitional dialogues.

My discussion of Socrates' avowals of knowledge, accordingly, also involves critiques of the attempts of other commentators to reconcile the inter-textual inconsistencies among Socrates' avowals and disavowals of ethical knowledge. My basic criticism of Brickhouse and Smith's

30 David Wolfsdorf, 'Socrates' Avowals of Knowledge', forthcoming, Phronesis 49 (2004a)

31 Socrates' sincere avowals of non-definitional ethical knowledge include Euthyd 296e3-297a1; Grg 521c7-d3; Prot 310d2-4; Ap 22c9-d3, and 29a4-b9.

32 Wolfsdorf (2004a); David Wolfsdorf, 'Interpreting Plato's Early Dialogues', forthcoming, Oxford Studies in Ancient Philosophy (2004b). Cf. also David Wolfsdorf, 'Plato and the Mouthpiece Theory', Ancient Philosophy, sup. vol., 19 (1999) 13-24. 
solution is that it rests on a weak philological argument. Precisely, Brickhouse and Smith's attempts to confirm that Socrates intends different meanings when he uses verbs of knowing with different sorts of adverbial expressions, for example ' $\omega \varsigma$ ' ('that') versus 'ö $\pi \eta^{\prime}$ ' ('how'), are untenable. In short, Socrates does not operate with a distinction between knowledge-that and knowledge-how. Therefore, specifically, the expression 'iò $\sigma \alpha \varphi \grave{\varepsilon} \zeta$ ' in (4) does not carry the particular epistemological weight Brickhouse and Smith have assigned to it; and, more generally, passages such as (3) and (4) must be interpreted as reflecting Socrates' commitment to (D) in those dialogues where he makes such claims.

The same result, then, applies to another passage akin to (D), of which Brickhouse and Smith attempt to offer an alternative interpretation:

(5) [Republic I] When I do not know (oi $\delta \alpha$ ) what the just is, I will not

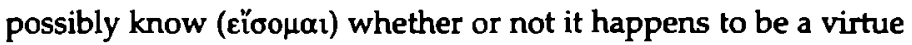
or whether or not one who has it is happy. ${ }^{39}$

On the basis of their distinction between clear and unclear knowledge, Brickhouse and Smith can interpret (5) as merely claiming that definitional knowledge of justice is necessary for clear knowledge of whether justice is a virtue or conducive to happiness. Accordingly, they claim that in stating (5) Socrates is expressing annoyance with himself for neglecting the 'procedural priority' of determining what $F$ is before determining these other questions. ${ }^{34}$

Indeed, at the end of the dialogue Socrates is annoyed with himself for attempting to determine whether the just man is better, stronger, and happier than the unjust man before he has determined what justice is. But since a Socratic distinction between clear and unclear knowledge or knowledge-that and knowledge-how is indefensible, (5) conveys more than this; it specifically conveys Socrates' belief in Republic I that if one does not know what justice is, one cannot know whether justice happens to be a virtue or whether one who has justice is happy. Socrates is annoyed with himself for the order in which the discussion has unfolded because he is committed to (D).

34 Brickhouse and Smith (1994), 55-60, especially 58. 
In contrast to Brickhouse and Smith's treatment of (5), it is noteworthy that Vlastos and Beversluis accept (5) as evidence of Socrates' commitment to (D). Moreover, they regard Republic I as an elenctic dialogue. Consequently, they are compelled to a different explanation to neutralize its significance. They argue that although Republic I is an elenctic dialogue, (5), including the section of Republic I in which it is embedded ( $345 \mathrm{a} 11 \mathrm{ff}$.), is a later addition that Plato appended to the end of the dialogue when, in the middle period, he prefixed the text to the rest of Republic. ${ }^{35}$ So, Beversluis, following Vlastos, writes:

[(5)] cannot belong to the composition which precedes it, for what it says (if I don't know what justice is, I cannot know if it is a virtue) implicitly contradicts [351a5-6], where "no one could not know that injustice is ignorance" and so, by implication, no one could not know that justice is knowledge, and therefore (350b5) virtue. ${ }^{36}$

Beversluis here depends on Vlastos' argument that at 351a5-6 Socrates avows knowledge of an ethical proposition. But Vlastos originally misinterpreted this passage. Vlastos cites: 'for injustice is ignorance - no one could still not know this ${ }^{37}$ and comments: 'that is to say, now everyone would know it: a fortiori so would Socrates.' But the passage does not claim that anyone who followed the argument including Socrates would know that injustice is ignorance. The citation has been lifted from a conditional statement in which it is embedded. When restored to its original context, it can be clearly seen not to be a knowledge claim. The full passage runs:

"But now," I said, "if justice is knowledge and a virtue, it will easily, I take it, be shown to be also a stronger thing than injustice, since injustice is ignorance - no one would still not know this. ${ }^{\prime 38}$

35 Beversluis (1987) 214 and 222, n 4. Although Beversluis does not give the full explanation I give here, he clearly follows Vlastos' treatment of the passage.

36 Vlastos (1985) 26, n 65, cited from Benson (1990) 26.

37 R I, 351a5-6

$38 R \mathrm{I}, 351 \mathrm{a3}-6$. Note the use of the optative in the last clause, which Vlastos mistranslates. 
The claim that injustice is ignorance depends upon the assumption that justice is knowledge. Socrates has argued for this, but he does not claim to know it. Since ignorance is the opposite of knowledge and injustice is the opposite of justice, it follows that if justice is knowledge, then injustice is ignorance. One could reasonably claim to know that injustice is ignorance if one claimed to know that justice is knowledge. But Socrates does not claim to know that. Consequently, (5) is consistent with the rest of Republic I, and so it cannot be dismissed as evidence of Socrates' commitment to (D).

\section{III i Further Evidence of (D)}

(1)-(5), then, provide solid evidence that, at least in Hippias Major, Meno, and Republic I, Socrates is committed to (PD). In' several other standardly accepted early definitional dialogues Socrates makes claims that, although strictly weaker than (P) or (D), suggest a commitment to (PD).

For instance, in Laches he says:

(6) Then isn't it necessary for us to begin by knowing (eiסéval) what

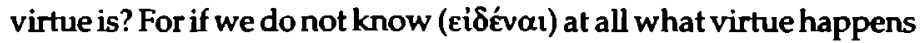
to be, how would we consult with anyone as to how he might best acquire it?

Interpreted strictly, this passage entails a narrower proposition than (D). Rather, (6) entails the proposition that if one does not know what virtue is, one cannot know how best to acquire it. So Vlastos and Beversluis argue that (6) is not evidence that Socrates in Laches is committed to (D) because (6) is insufficiently general. ${ }^{40}$ However, as Benson has indicated, an immediately preceding passage makes clear that (6) reflects Socrates' commitment to a broader principle:

39 La $190 \mathrm{~b} 7-\mathrm{c}$

40 Vlastos claims that it is insufficiently general. Beversluis writes: 'Socrates does not put forth the completely general assertion that if you do not know the definition of $F$, you cannot know anything whatever about $F$ or that anything whatever is [an example of] $F$. His claim is very specific and heavily qualified: if you do not know the nature of virtue, you cannot usefully advise anyone about how best to achieve it.' (1987, 215, cited from Benson, 1990, 37) 


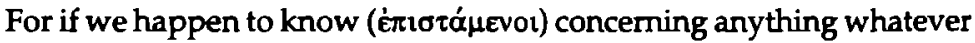
that its being added to something makes that thing to which it is added better, and further, we are able to cause that thing to be added to it,

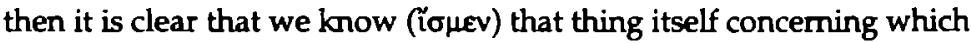
we advise how someone might best and most easily attain it ... Then

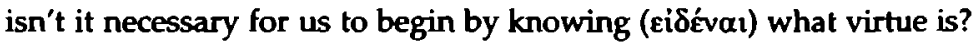
For if we do not know (eídéval) at all what virtue happens to be, how would we consult with anyone as to how he might best acquire it? ${ }^{41}$

In Lysis, Socrates says:

(7) We have been ridiculous ... For those who leave us will say that we think we are friends with each other - yet we have not been able to discover what a friend is. ${ }^{42}$

This passage does not provide strong evidence of Socrates' commitment to (P). But in light of (1)-(6), a good explanation for why Plato makes Socrates say (6) is that he is committed to (P).

Benson also cites the following passage from Charmides as evidence of Socrates' commitment to (D):

(8) I don't know (oîda) if I have self-control or if I don't have it. How would I know (Eíseinv) that concerning which neither of you is able to determine what it is, or so you say ? $^{43}$

In one respect (8) is remarkably weak evidence of Socrates' commitment to (D): Socrates is not the speaker, Charmides is. On the other hand, the fact that Charmides and not Socrates is the speaker actually helps clarify why Socrates would make claims like (1)-(7). (8) occurs at the end of the investigation, after Charmides, Critias, and Socrates have failed to articulate a mutually satisfactory definition of self-control. As a result, Charmides realizes that in a case where one recognizes that one does not know what a given property is, one will not know whether one possesses that property. Unlike most of his interlocutors at the beginning of investigations, Socrates begins with a keen awareness of the difficulties 
of defining the virtues. Consequently, he is already a veteran of the state in which Charmides here finds himself.

\section{III ii Further Evidence of (P)}

In Euthyphro the following three passages provide evidence that Socrates is committed to $(\mathrm{P})$ :

(9) [Euthyphro] Then teach me what this form itself is so that looking to it and using it as a paradigm, I can say that that which is such as it is, whether done by you or someone else, is holy and that which is not is unholy."

(10) [Euthyphro] For if you did not clearly know the holy and the unholy, it is not possible that you would attempt to prosecute your aged father for murder on behalf of a hired laborer, but you would have feared the gods, risking that you did not do this correctly, and would have been ashamed before men. Now, I know well that you think you know clearly the holy and the unholy. ${ }^{45}$

(11) [Euthyphro] [EU: My relatives say] that it is unholy for a son to prosecute his father for murder - knowing (eioótes) poorly, Socrates, how the divine is disposed to the holy and the unholy. [so:] Euthyphro, do you think you have such accurate knowledge

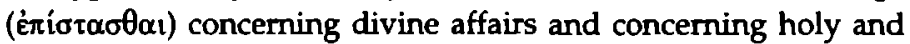
unholy things that, the situation being as you say, you do not fear that by prosecuting your father you may be doing something unholy? [EU:] I would be useless, Socrates, and no different from the average man if I did not accurately know (eíeinv) all such things ... [so:] Then tell me what you just now asserted you knew (eidéval) clearly, what sort of things you say the sacred and the sacrilegious are, in the case of murder and all other actions. ${ }^{46}$

44 Euthphr 6e3-6

45 Euthphr 15d4-e1

46 Euthphr 4d9-5d1 
It has been argued that these passages commit Socrates to two principles weaker than $(\mathrm{P})$. One is the sufficiency of definitional knowledge of $F$ for knowledge of instances of $F$ : if one knows what $F$ is, one knows, for any $x$, whether $x$ is an instance of $F$. The other is the necessity of definitional knowledge of $F$ for expertise regarding $F$ : if one does not know what $F$ is, one cannot know, for any $x$ that is a controversial or borderline case, whether $x$ is an instance of $F$.

Beversluis and Vlastos as well as Santas ${ }^{47}$ regard the second principle as the correct inference from (10) in view of the extraordinary and controversial character of Euthyphro's case. They argue that Socrates' point in expressing (10) is that definitional knowledge of $F$ distinguishes the expert from the average person and specifically that the special value of the expert lies in his ability to adjudicate difficult cases. Accordingly, they claim that Socrates is not committed to the necessity of definitional knowledge for knowledge of all instances of $F$. Since, strictly speaking, (9) and (11) only indicate that definitional knowledge of $F$ is sufficient for knowledge of instances of $F$, they argue that it is possible for one without definitional knowledge to know some uncontroversial instances of $F$. These instances may then be used in the pursuit of definitional knowledge of $F$.

Given Socrates' commitment to (P) and (D) in other dialogues, it would be odd for him to be committed to weaker principles in Euthyphro. The argument must be wrong. To see why, consider the following. The argument assumes that one may acquire knowledge of instances of $F$ in the absence of definitional knowledge of $F$. But how - according to the evidence of the early dialogues - might such acquisition take place? Two considerations undermine the possibility that other means exist.

First, consider the fact that the investigations of $F$ in the early definitional dialogues typically involve the rejection or problematization of conventional views about $F$ and that they advance or advance in the direction of unconventional views about $F$. As such, the investigations suggest that conventional, especially pre-reflective, assumptions about $F$, and specifically assumptions of knowledge about $F$, are liable to be undermined. Note that even and especially alleged experts have their pretensions to knowledge of $F$ repeatedly undermined. Accordingly, the

47 Gerasimos Xenophon Santas, 'The Socratic Fallacy', Journal of the History of Philosophy 10 (1972) 124-41 
early dialogues suggest that it is not merely borderline cases that warrant scrutiny, but mundane cases as well. A striking example is Socrates' novel conception of justice in Republic I. Most Greeks would have assumed that instances of harming one's enemy exemplified justice. But Socrates' argument that it is never just to do harm contradicts this view. In short, the early dialogues suggest that while everyone has beliefs and strong convictions about what counts as an instance of $F$, few if any have knowledge.

Second, consider the common Greek practice of seeking or acquiring information from the divine. If a person believed that he received a message $p$ from a divine source, perhaps he would believe that he knew that $p$. But the early dialogues undermine the view that such a person would have knowledge. Consider the following evidence from Apology. In that text Socrates claims that the divine does not lie: '[the god ( $\dot{0} \theta$ cós) ] cannot be lying, for that it not lawful ( $\theta$ éuls) for it. ${ }^{148}$ Elsewhere in Apology he criticizes the jurors for fearing death since they do not know what death is. ${ }^{49}$ This rebuke suggests a principle related to (D): if one does not know what death is, one cannot know whether it is good or bad. Toward the end of his speech, Socrates claims that death is a good thing and that

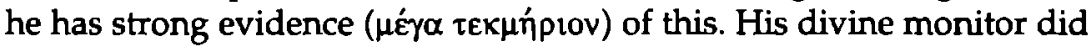
not prevent him from coming to court and delivering his speech; yet it would have if the outcome of the action were to have been bad. ${ }^{50}$ Since Socrates is being condemned to death, death cannot be a bad thing. However, even though Socrates expresses his strong belief in this proposition, in the final line of the text he claims that whether death is a good thing is unclear to all but the divine. ${ }^{51}$ Accordingly, he concludes his speech with the belief that he does not know whether death is good. ${ }^{52}$

48 Ap 21b5-7. Cf. Mark McPherran, 'Elenctic Interpretation and the Delphic Oracle', in Gary Alan Scott, ed., Does Socrates Have a Method? (University Park: Pennsylvania State University Press 2002), 114-44, at 122-3.

49 Ap 29a3-b2

50 Ap $40 \mathrm{cl}-2$

51 Ap 42a2-5

52 In disavowing knowledge of the value of death in Apology, then, Socrates' expressed grounds are that he does not know what death is. Note that this cannot be the only reason since knowledge of death would be necessary, but not sufficient for knowledge of the value of death. While (D) states that definitional knowledge of $F$ is 
Yet the divine cannot be deceiving him. (I discuss below why Socrates does not believe he knows that death is a good thing.)

Presently, note that the preceding two considerations lend support to the view that (9)-(11), like (1)-(8), actually reflect Socrates' commitment to a principle stronger than the sufficiency of definitional knowledge of $F$ for knowledge of instances of $F$ and the necessity of definitional knowledge of $F$ for knowledge of controversial instances of $F$. (9)-(11) reflect Socrates' commitment to (P); for although, strictly speaking, (9) only commits Socrates to the sufficiency of definitional knowledge for knowledge of instances of $F$, the foregoing considerations suggest that there are in fact no other means of acquiring knowledge of instances of $F$. And so although, strictly speaking, (10) only commits Socrates to the necessity of definitional knowledge for knowledge of difficult cases of $F$, the evidence indicates that there are no other means of acquiring knowledge of 'common' instances of $F$.

\section{IV $i$ Prior on the Interpretation of (PD)}

Granted, then, in a number of dialogues Socrates makes claims that reflect his commitment to (PD). How is this commitment to be understood, and does it ensnare him in the kind of methodological difficulties to which Geach first drew attention?

Benson, who has thoroughly defended Socrates' commitment to (PD) ${ }^{53}$ argues that Socrates does not violate this commitment because in the definitional dialogues he does not pursue definitions of $F$ so much

necessary for knowledge of $F$ 's properties, it does not state that definitional knowledge of $F$ is sufficient for knowledge of $F$ 's properties. Surely, definitional knowledge of $F$ is necessary and sufficient for knowledge of $F$ 's essential properties. But if $P$ is a non-essential property of $G$, then in order to know whether $F$ has $P$, one may have to know what $P$ is in addition to knowing what $G$ is. So here in Apology the reason Socrates gives for not knowing whether death is good is that he does not know what death involves. But if goodness is not an essential property of death (as it does not seem to be), then he must need to know what goodness is. In other words, given (P), he needs to know what goodness is to know that death is an instance of it. The fact that Socrates does not make this explicit in Apology can easily be explained on dramaturgical grounds.

53 Benson (1990) 
as test the claims of alleged experts to definitional knowledge by assessing the consistency of their beliefs regarding $F$. Benson's argument is untenable. As I have recently demonstrated, Socrates does not merely test his interlocutors, he jointly, cooperatively pursues definitional knowledge with them. ${ }^{54}$

An alternative is that Socrates pursues definitional knowledge on the basis of beliefs, not knowledge. Burnyeat and Irwin first articulated a position of this kind, ${ }^{55}$ and Prior has recently developed it. ${ }^{56}$ Prior's view

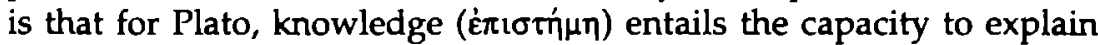
what is known. In other words, knowledge requires an explanation ( $\lambda$ óyos). As such, Prior calls the kind of knowledge with which Plato is concerned 'rational knowledge'. This differs from the kind of knowledge to which Geach refers when he says that we 'know heaps of things without being able to define the terms in which we express our knowledge.' At least, Prior would argue the following. A definitional account is not necessary for every kind of knowledge claim, but it is for (non-definitional) ethical knowledge claims. And for other kinds of knowledge claims, some form of explanation remains necessary. Again, one does not have knowledge without being able to give some kind of explanation of the thing of which one has $\dot{\varepsilon} \pi \mathrm{\sigma} \sigma \dot{\eta} \mu \eta .{ }^{57}$ Indeed, Prior suggests that the link

54 See n 9, and cf. also David Wolfsdorf, 'Comments on Benson', Proceedings of the Boston Area Colloquium in Ancient Philosophy 19 (2003a) 127-43.

55 M.F. Burnyeat, 'Examples in Epistemology: Socrates, Theaetetus, and G.E. Moore', Philosophy 52 (1977) 381-98, Terence Irwin, Plato's Moral Theory (Oxford. Clarendon Press 1977), 41.

56 William J. Prior, 'Plato and the "Socratic Fallacy" ', Phronesis 43 (1998) 97-113

57 On this cf. J.M.E. Moravcisk, 'Understanding and Knowledge in Plato's Philosophy', Neue Hefte für Philosophie 15-16 (1978) 53-69; Gail Fine, 'Knowledge and Logos in Theaetetus', Philosophical Review 88 (1979) 367-97; J. Moline, Plato's Theory of Understanding (Madison: University of Wisconsin Press 1981), esp. 33-43; Gail Fine, 'Knowledge and Belief in Republic V-VI', in Stephen Everson, ed., Epistemology (New York: Cambridge University Press 1990), 106; Hugh H. Benson, Socratic Wisdom (New York: Oxford University Press 2000). Prior also cites Meno 98a; Phd 76d; $R$ VII, 531e, 534b; Tht 202d (1998, 107 and n 18). Brickhouse and Smith's (1994) concept of clear knowledge, wisdom, or knowledge-how also entails the ability to give an account or explanation. However, as I have indicated, the problem with their position is that Socrates does not operate with two distinct concepts of knowledge. 
between knowledge and explanation 'may have been analytic' ${ }^{58}$ Prior's response to Geach is well encapsulated in the following remarks:

It is a perfectly intelligible procedure, one followed in all forms of classificatory endeavor, to consider many alleged examples of a given term in the hope of coming up with a general criterion or general criteria of classification. Once one has developed or discovered such criteria, one can then use them to sort through the initial set of alleged examples and separate those that truly belong to the class from those that merely appear to. It is not necessary to know beforehand that all of the putative examples in the initial set are genuine. It is not necessary to know, in the case of any particular example, that it is genuine. It is not even necessary to know that any of the examples in the initial set is genuine (though if one's initial choice of putative examples is that unfortunate the classificatory project is unlikely to reach a successful conclusion). All that is necessary is that one have a reasonable amount of confidence that at least some of the examples in the initial set are genuine. It is the discovery of general criteria, which is the aim of the classificatory project, that will convert this confidence into knowledge; so it is hard to see how one could know, in advance of the discovery of these criteria, that a given example is a genuine one."

Some have spoken of the kind of knowledge that Prior ascribes to Plato as not merely rational, but scientific. But that characterization is misleading. Note that Socrates makes many ordinary knowledge claims throughout the early dialogues. For example, in Euthydemus:

"Come, then, answer me this," [Euthydemus] said. "Do you know

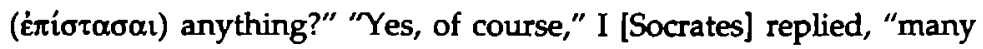
things, in fact, although insignificant ones."

Socrates is not alluding to anything distinctly scientific here. Even if all instances of knowledge entail the ability to give some kind of explanation, the ability to provide a definition needn't be a necessary component of explanation in all cases. Prior notes this: 
The right response to the question "How do you know it's raining?" might be, "T'm looking out the window at the raining coming down right now." The right response to "How do you know Susan lives on this street?" might be, "I've given her a ride home dozens of times.",t1

In cases such as these the appropriate explanations are non-definitional. So in Protagoras, when Socrates confirms that he knows Simonides' Scopas ode - 'Do you know the ode, or should I recite the

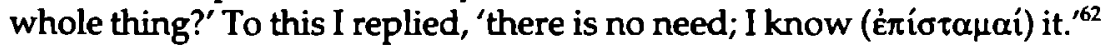
- his knowledge surely does not entail the ability to define anything, but, presumably, just the ability to recite the ode. In short, knowledge requires explanation, but the kind of explanation required depends on the content or object of knowledge.

Socrates' remarks in Euthyphro shed some light on this point:

If you and I were to disagree about number, for instance, which of two numbers were greater, would the disagreement about these matters make us enemies and make us angry with each other, or should we not quickly settle it by resorting to arithmetic? ... Then, too, if we were to disagree about the relative sizes of things, we should quickly put an end to the disagreement by measuring? ... And we should, I suppose, come to terms about relative weights by weighing? ... But about what would a disagreement be which we could not settle and which would cause us to be enemies and be angry with each other? Perhaps you cannot give an answer offhand; but let me suggest it. Is it not about right and wrong and noble and disgraceful and good and bad? ${ }^{63}$

It is made explicit here that there are different sorts of procedures for the dis/confirmation of different sorts of knowledge claims. And this suggests that the character of explanation for a given kind of knowledge claim will be related to the character of the dis/confirmation procedure pertinent to that domain of knowledge.

Consider this suggestion in light of the following remarks from Gorgias. Socrates argues that the conditions of one who has learned and one who has come to believe are not identical. He explains the distinction

61 Prior (1998), 104

62 Prot 339b4-5

63 Euthphr 7b7-d2 
with the claim that belief can be true or false, whereas knowledge can only be true. ${ }^{64}$ This implies that knowledge results from learning ${ }^{65}$ Assuming that learning involves coming to know something through a particular explanatory procedure, then that which has come to be known will entail the explanation by which it was learned. Given that much of knowledge learned is not learned through definition, it should not be expected that all knowledge entails a definitional explanation.

As the examples from the Euthyphro passage indicate, in many cases dis/confirmation procedures are uncontroversial. As such, they do not arouse (Socrates') epistemological curiosity - even though, with the hindsight of the history of epistemology, we can see how fruitful examination of them has proven to be. In the early dialogues Socrates does not explore the broad epistemological question of how various things are known or what different kinds of epistemic explanations reveal about kinds of knowledge or knowledge in general. To broach these questions would be to open the field of epistemology in the wide sense that we now take for granted. Unlike Descartes, Socrates does not question the grounds of ordinary knowledge or belief. He knows that his name is 'Socrates', that he is an Athenian, a father, that this is water, that is wine. But such knowledge simply does not arouse suspicion or interest. It is rather in the domain of ethical claims that his epistemological interest is piqued. As he notes in the Euthyphro passage, the dis/confirmation procedure here is obscure, and indeed, remarkably so. Consequently, it is unclear how to settle ethical disagreement or simply to dis/confirm ethical claims.

\section{IV ii Definitions and Standards of Evaluation}

I submit that the appeal to definitions is Socrates' answer to the problem of adjudicating and dis/confirming ethical knowledge claims (at least non-definitional ethical knowledge claims). As he says elsewhere in Euthyphro, the Form ( $\varepsilon \hat{i} \delta \circ \varsigma$ ) - which is the object of definition - serves as a standard ( $\pi \alpha \rho \alpha \dot{\delta} \varepsilon i \gamma \mu \alpha)$ on the basis of which to judge. In a general sense, then, it is this that leads Socrates to the adoption of (PD), that is, to the adoption of the view that the kind of explanation needed for 
knowledge of non-definitional ethical propositions is definitional knowledge.

More specifically, the reason for Socrates' adoption of this particular position can be clarified by the following considerations. First, the kind of explanatory account that Socrates conceives as necessary is relatively theoretical. Contrast this with the more concrete, straightforwardly empirical account we have from Prior's example of the claim to know that it is raining: I know it because I see the raining coming down. In the case of (non-definitional) ethical propositions the distinct dis/confirmation procedure is due to the nature of ethical kinds themselves. As Prior notes: 'Piety and courage are not transparent moral properties which only need to be observed in a select number of cases to be understood. ${ }^{166}$ We might simply say that ethical properties are not transparent properties that may be learned through some relatively simply procedure, say, ostensive definition.

Of course, the same holds for a large number of others entity types. Accordingly, knowledge of a range of other entities should entail correspondingly theoretical explanations, perhaps specifically definitional accounts. Again, in the early dialogues, Socrates is not much concerned with non-ethical knowledge. Still, in Protagoras and Gorgias, he makes two claims reminiscent of (D) whose subjects are not ethical virtues:

[Protagoras] I would be surprised if you knew (oio $\theta \alpha$ ) what a sophist is. But if you don't know (árvoeis) this, then you don't know (àrvoeis) whether the person to whom you are giving your soul is good or bad. ${ }^{67}$

[Gorgias] I will not answer him whether I think rhetoric is fine or mean until I answer first what it is, for it would not be just. ${ }^{68}$

In light of these examples, it is also fitting to recall Socrates' epistemic attitude in Apology toward the value of death. Why does Socrates conclude his speech with the words 'But now the time has come to go away. I to die and you to live; but which of us goes to the better lot is known to 
none but the divine' $?^{69}$ That is to say, why does Socrates disavow knowl-

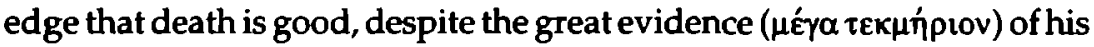
divine sign, which, as we noted above, is an authoritative source that cannot lie? The preceding considerations suggest that Socrates believes that he cannot give the right sort of explanatory account. To know that death is good surely requires an explanation of what occurs in death. But Socrates' divine monitor has not conveyed that. So, it seems, for ordinary human beings this particular piece of eschatological knowledge cannot be acquired. Note that in this instance, in contrast to the preceding cases of sophistry and rhetoric, it is because of experiential limitations, not theoretical difficulties, that such knowledge is conceived as unavailable.

Second, Socrates' commitment to (PD) seems closely linked to certain of his semantic and metaphysical commitments. Socrates is committed to the so-called 'single character principle'. This states that whatever is correctly called ' $\rho$ - where ' $\rho$ is the adjective corresponding to the general term ' $F$ ' - has some one character $F$, which is the same character in the case of all $f$ things, and where all $f$ things are $f$ in virtue of having this character. ${ }^{70}$ Evidence for Socrates' commitment to this principle is derived from a variety of claims, including the following from Hippias Major: 'just men are just because of justice'; '7 'wise men are wise because of wisdom'; 'all good things are good because of goodness'; ', all beautiful things are beautiful because of beauty'.$^{74}$ The significance of such claims for Socrates' commitment to (PD) is that the Form (or character) is conceived as the $\alpha i \tau i \alpha$ or entity responsible for things being $f$. Thus, an account of the Form, which is a definition, serves to explain why, say, $x$ is $f$. In other words, it serves to explain why this or that is or is not an instance of $F$.

70 This principle is formulated by Vlastos in Platonic Studies, $2^{\text {nd }}$ ed. (Princeton, NJ: Princeton University Press 1981), at 128, n 28, and adopted by Paul Woodruff, The Socratic Approach to Semantic Incompleteness', Philosophy and Phenomenological Research 38 (1978), at 457.

71 Hp Ma 287c2-3

72 Hp Ma 287c5

$73 \mathrm{Hp} \mathrm{Ma} \mathrm{287c5-6}$

74 Hp Ma 287c8-d1; cf. Euthphr 5d1-5 and Meno 72a6 ff. 
The foregoing particularly illuminates Socrates' commitment to (P). Presumably, the same sort of account should hold for his commitment to (D). That is, the proper explanation for a claim such as that $F$ has a certain property $G$ is a definitional account of $F^{75}$ We do not, however, find many claims in the early definitional dialogues such as that $F$ has the property $G$ because of $F$. A possible example occurs in Euthyphro where Socrates claims that the holy is god-beloved because it is such as to be loved (oiov $\varphi\left(\lambda \in \hat{\sigma} \sigma \theta \alpha\right.$ ). ${ }^{76}$ But for the most part, we just encounter claims like 'I am so far from knowing whether or not virtue is teachable that I do not at all know what virtue itself is. ${ }^{\prime \prime}$ In other words, we just find claims that reflect (D).

In sum, Socrates' commitments to (P) and (D) are related to his metaphysical commitments, precisely to the following two: particulars have their properties in virtue of Forms, and Forms have at least their essential properties in virtue of themselves. Note, however, that the second conjunct is complicated by the following consequence of (PD). To the extent that $F$ has certain ethical properties, (P) and (D) are inter-entailing. $(\mathrm{P})$ states that definitional knowledge is necessary for knowledge of instances of $F$, and (D) states that definitional knowledge of $F$ is necessary for knowledge of $F^{\prime}$ s properties. But, insofar as $F$ has essential ethical properties, $F$ is an instance of these properties. For example, if self-control is beautiful and if (P), then order to know what self-control is, it is necessary to know what the beautiful is. Similarly, if justice is a virtue and (P), then in order to know what justice is, it is necessary to know what virtue is. Accordingly, definitional knowledge of the beautiful and virtue (which is to say the good) are necessary for definitional knowledge of self-control, justice, holiness, and courage unless of course the virtues are identical. Similarly, unless the beautiful

75 Cf. Prior's remark: 'Consider the question from the Meno: "how can I know a property of something when I don't even know what it is?" (71b) What this implies in context is that Socrates does not believe he can know whether virtue is teachable without knowing what the nature of virtue is. I suggest that what this implies is that Socrates thinks he can have no logos, no rational account of the teachability of virtue without a logos of the nature of virtue. In general, he can have no rational account of the properties of an object without having a rational account of the nature of the object' $(1998,108)$.

76 Euthphr 11a4-5

77 Meno 71a5-7 
and the good are identical, definitional knowledge of the one is necessary for definitional knowledge of the other.

Socrates' claim (5) in Republic I that definitional knowledge of justice is necessary for knowledge of whether justice is a virtue may seem inconsistent with this conclusion. But consider the following propositions:

$\left(D_{R}\right)$ Definitional knowledge of justice is necessary for knowledge of whether justice is a virtue.

$\left(\mathbf{P}_{R}\right)$ Definitional knowledge of virtue is necessary for knowledge of whether justice is a virtue.

Definitional knowledge is necessary and sufficient for knowledge of whether a given entity $x$ is an instance of virtue. But it is not sufficient for knowledge of the identity of $x$. Similarly, definitional knowledge of a parallelogram may be necessary and sufficient for knowledge of whether a given shape is a parallelogram. But if $x$ is a square, definitional knowledge of a parallelogram is insufficient for knowing that. Accordingly, $\left(P_{R}\right)$ does not state that definitional knowledge of virtue is necessary and sufficient for knowledge of whether justice is a virtue. And similarly, $\left(D_{R}\right)$ does not state that definitional knowledge of justice is necessary and sufficient for knowledge of whether justice is a virtue in addition, one needs to know what virtue is. This suggests that knowledge of the most general ethical kind, namely the good, is necessary for knowledge of $F$. And although in the early dialogues Socrates never says this, it is noteworthy that in Republic VI he suggests it:

[Y]ou have certainly often been told that the greatest lesson is of the Form of the Good, from which things that are just and so on derive their usefulness and value. ${ }^{78}$

Understand, then ... that by the other section of the intelligible [that is, the section of the divided line reserved for non-mathematical Forms, knowledge of which is gained through intellection (vónois)] I mean that which reason itself lays hold of through the power of dialectic, treating the hypotheses not as first principles, but as genuine hypotheses, like 
first steps and points of departure, until it comes to that which requires no hypothesis, the first principle of everything [namely that Form of the Good]. And once it has reached that, it once again grasps those things most proximately related to it and so proceeds downward to the conclusion, making no use of anything sensible, but using Forms it reaches its conclusion to Forms through Forms. ${ }^{\text {" }}$

\section{The Pursuit of Definitional Knowledge}

With the view that the pursuit of definitional knowledge of $F$ might only be finally realized once knowledge of the Form of the Good is attained, we return, in a manner, to Geach's original concern. Granted, the knowledge of non-definitional ethical propositions requires a definitional explanation and so definitional knowledge. But now, definitional

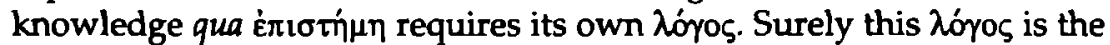
ability to state the given definition, or, if the foregoing consideration is true, it requires the ability to state the definition of the superordinate Form of the Good. I do not hope to settle here which. But in either case, how is the definition to be pursued? In other words, by what procedure can claims regarding the identity of $F$ be dis/confirmed?

The appropriate place from which to begin consideration of these questions would seem to be the early definitional dialogues themselves, for, after all, they attempt to define $F$. Yet when we turn to these texts for help, they do not quite provide the help we need. I have in mind here the six standardly accepted early definitional dialogues: Charmides, Laches, Euthyphro, Hippias Major, Meno, and Republic I. ${ }^{80}$ On my count, in these texts twenty-five definitions of $F$ are proposed and evaluated. ${ }^{81}$

79 R 511b3-c2

80 I omit Lysis merely because it is disputable whether friendship is a virtue and whether Lysis is a definitional dialogue. I believe both are, but inclusion of Lysis would not affect the following discussion.

81 Four in Charmides: quietness, modesty, doing one's own thing (reinterpreted as doing what is good); and self-knowledge (reinterpreted as the knowledge of knowledge). Three in Laches: remaining in rank, defending against the enemy, and not fleeing; toughness of the soul; and the knowledge of what is to be feared and dared. Four in Euthyphro: prosecuting one who commits sacrilege, regardless of one's relation to the offender; that which is god-beloved; that which is loved by all the 
As we have seen, both Geach and Prior speak of the use of examples in the pursuit of definitions. '[Geach:] If the parties to a discussion are agreed, broadly speaking, about the application of a term, then they can set out to find a criterion for applying it that shall yield the agreed application.' '[Prior:] It is a perfectly intelligible procedure, one followed in all forms of classificatory endeavor, to consider many alleged examples of a given term in the hope of coming up with a general criterion or general criteria of classification.' In fact, Socrates rarely uses examples in the manner that Geach and Prior suggest one might or should. That is to say, Socrates rarely generates a set of putative examples of $F$ and engages his interlocutor in a consideration of what all such examples have in common.

In formulating and evaluating the twenty-five definitions, there is only one case of this kind. That is the example (cited at the beginning of this paper) where in response to Laches' first definition of courage Socrates enumerates several other act-types whose agents may all be characterized as courageous and then suggests that Laches consider what the various agents have in common. It is noteworthy that Prior cites this as an example and mistakenly claims that 'this is in fact the procedure followed by Socrates in the early dialogues. ${ }^{282}$

One other seemingly related case is Socrates' response to Euthyphro's first definition. There, Socrates says that he did not ask for one or two of the many holy things, but that single Form that they all have in common. ${ }^{83}$ One might take Socrates to be implying that Euthyphro needs to consider a broader range of holy entities and then reflect on what they all share. But if that were the case, one would expect him to enumerate several other examples, as he does in Laches. Instead, his response is

gods; attention to the gods (reinterpreted as service to the gods). Seven in Hippias Major: a beautiful young woman; gold; to be rich, healthy, honored by the Greeks, to live to old age, and to bury one's parents; decorousness; utility (reinterpreted as power); benefit; aesthetic pleasure (reinterpreted as beneficial pleasure). Three in Meno: managing political affairs (for a man) and managing domestic affairs (for a womar); being able to govem people; desiring what is fine and being able to procure it. Four in Republic I: telling the truth and returning what one takes; doing what is fitting (reinterpreted as aiding friends and harming enemies); aiding a friend who is good and harming an enemy who is bad; that which is good for the stronger.

82 Prior (1998), 111 
principally an attempt to clarify for Euthyphro the fundamental ontological distinction between instances or types of $F$ and $F$ itself. ${ }^{84}$

In the early definitional dialogues, examples are, for the most part, used not to generate definitions of $F$, but to refute the definientia. For instance, Hippias defines the beautiful as a beautiful young woman. In response, Socrates cites the example of a goddess to show that beautiful young women are not purely beautiful; he has assumed that the definiendum is. Similarly, Charmides defines self-control as modesty. In response Socrates cites the example of a beggar to show that modesty is not necessarily good; he has assumed that the definiendum is.

Of course, the use of examples to refute definitions may imply characteristics of the definienda themselves. However, as the two preceding examples suggest, it is not putative examples of $F$ that govern the pursuit of definitions, but what I have elsewhere called ' $F$-conditions', that is, conditions for the identity of $F$ that the definientia are supposed to satisfy. ${ }^{85}$ For example, in response to Laches' second definition of courage as toughness of the soul, Socrates elicits Laches' assent to the premise that courage is beautiful; and this premise then serves to undermine the proposed definition by showing that in certain cases toughness is not beautiful.

Granted the role of $F$-conditions in the pursuit of definitions, it is also important to emphasize that the $F$-conditions themselves are not derived from putative examples of $F$ in the way that Geach or Prior might suggest that examples could be used. For the most part, Socrates simply introduces $F$-conditions without defense or explanation. This is not meant to convey that Socrates takes them to be self-evident or that he lacks some resources to defend them. It is simply that Socrates typically argues on the basis of $F$-conditions; he does not argue to them.

Given Socrates' commitment to (D), he cannot know the F-conditions he employs. Moreover, we can accept, with Prior, that the lack of such knowledge does not per se incapacitate the pursuit of definitional knowledge, for the knowledge that Socrates seeks is rational knowledge. Thus, Socrates does not commit an egregious fallacy by committing himself to $(\mathrm{P})$, while employing examples of $F$ that he assumes he knows. Still,

84 On this point, cf. David Wolfsdorf, 'Understanding the "What-is-F?" Question', Apeiron 36 (2003c) 191-204.

85 Wolfsdorf (2003b), cf. also Wolfsdorf (2003a). 
I do not see that the real thrust of Geach's accusation has been neutralized.

The empirical scientist may attempt to derive general criteria from a sample set; and, yes, her samples need not all be genuine. But for her enterprise to succeed, the set must contain at least a preponderance of genuine examples. In this case, the sample set provides a secure evidential base from which to make inferences to general criteria. But in Socrates' case, there is no secure set of genuine instances of $F$, nor does Socrates operate as though there were. It is his set of $F$-conditions that explicitly regulates his pursuit of definitions. But what reason do we have to believe that these serve as a secure evidential base? They may well be the most reasonable propositions about $F$ that Socrates can find, and his interlocutors almost always agree with them. However, we need a reason to believe that they are true. In the early dialogues I do not see that any compelling reason is given. This is precisely the problem to which an ethical realist such as Socrates must answer. ${ }^{86}$

\section{Boston University Department of Philosophy 745 Commonwealth Avenue Fifth Floor Boston, MA 02215 dwolf@bu.edu}

86 One noteworthy attempt to develop a Davidsonian style justification for Socrates' ethical realism is Theodore Scaltsas, 'Socratic Moral Realism: An Alternative Justification', Oxford Studies in Ancient Philosophy 7 (1989) 129-50. While intriguing, his attempt seems to me weak in two fundamental respects. First, it depends on a number of dubious assumptions inherited from Vlastos regarding pre- and postGorgias early dialogues and Socrates' commitments in these respective sets. (For a sound criticism of these see Brickhouse and Smith, 'Vlastos on the Elenchus', Oxford Studies in Anctent Philosophy 2 [1984] 185-96.) Second, however successful Davidson's coherence theory may be for non-ethical beliefs, it is precisely the cognitivism of Socrates' ethical beliefs that needs justifying. This is not attempted. Note Scaltsas' remark, 'to justify the Adequacy Assumption [i.e., that there are enough true beliefs in a person to entail the negation of false beliefs] in the case of moral beliefs (which is Socrates' concern) on the basis of Davidson's epistemology would require a somewhat longer story, within the Davidsonian system, on moral cognitivism. This will not be attempted here but the need for it is noted' $(1989,143)$. 
